\title{
REENGINEERING CONSTRUCTION PROCESSES IN THE ERA OF CONSTRUCTION 4.0: A LEAN-BASED FRAMEWORK
}

\author{
Makram Bou Hatoum ${ }^{1}$, Hala Nassereddine ${ }^{2}$, and Fazleena Badurdeen ${ }^{3}$
}

\begin{abstract}
Industries around the world continue to be reshaped, and the construction industry is no exception. Being one of the oldest industries, construction did indeed undergo major transformations over the years. However, for the past few decades, traditional businessas-usual in construction has reached a stagnation point, adding pressure on organizations to rethink their current processes. Two major transformations changed and continue to change the landscape of the construction industry: Lean Construction and Construction 4.0. While Lean has taken a hold of construction, Construction 4.0, a counterpart of Industry 4.0, is a growing transformation that leverages the power of technology. While the importance of Construction 4.0 has been highlighted, the "how" component of achieving a Construction 4.0 state has not been yet discussed. A process reengineering methodology is needed to assist construction companies in adopting technologies, especially since the existing construction processes have been mostly designed before current technologies became available. Therefore, this paper proposes a holistic conceptual framework to reengineer construction processes in the Construction 4.0 era. The proposed Construction 4.0 Process Reengineering (CPR4.0) framework, which embodies the Futures Triangle methodology, is inspired by Kurt Lewin Change Management Model, and consists of three phases that build on existing reengineering methodologies, people-process-technology methodology, and Lean principles.
\end{abstract}

\section{KEYWORDS}

Lean construction, process reengineering, Construction 4.0, futures triangle, lean framework.

\section{BACKGROUND}

Different businesses across major industries are constantly undergoing significant changes. Driven by the growing global competition, increased complexity of business environments, added pressure from customer expectations, and the emergence of new technology, businesses are changing existing processes to be more dynamic and responsive (Adesola and Baines 2005). As a result, various methodologies to reengineer processes were developed and the concept of business process reengineering (BPR)

Ph.D. Candidate, Department of Civil Engineering, University of Kentucky, Lexington, KY, USA, mbh.93@uky.edu, orcid.org/0000-0002-8824-3941

2 Assistant Professor, Department of Civil Engineering, University of Kentucky, Lexington, KY, USA, hala.nassereddine@uky.edu, orcid.org/0000-0001-7952-5034

3 Professor and Director of Graduate Studies for Manufacturing Systems Engineering, University of Kentucky, Lexington, KY, USA, badurdeen@uky.edu, orcid.org/0000-0002-8471-1074 
emerged. BPR is defined as "the fundamental rethinking and radical redesign of business processes to achieve dramatic improvements in critical, contemporary measures of performance, such as cost, quality, service, and speed" (Hammer and Champy 2009). The major phases of BPR can be summarized in a five-step-continuous-improvement-like cycle: (1) Initiation of the reengineering or improvement process, (2) Diagnosis through analyzing the current state and finding areas of improvement, (3) Design of the future state, (4) Implementation of the future state, and finally (5) Evaluation and continuous assessment of the new process (Adesola and Baines 2005; Widodo et al. 2020).

The construction industry is no exception to the array of industries and businesses that are constantly facing a dynamic environment. It has been well documented that the traditional business-as-usual in the construction industry has reached a stagnation point there is a pressing need to increase productivity, improve project performance, address the labor shortage, reduce fragmentation, introduce standardization, address resistance to change, and increase collaboration (Barbosa et al. 2017; Bou Hatoum and Nassereddine 2020; Lau et al. 2019; Mellado and Lou 2020; Nassereddine 2019; Sawhney et al. 2020a). Such needs provide a call for action, leading academicians and practitioners to examine other industries for opportunities to innovate for the construction industry. One industry that has been considered the treasure trove of innovation for construction is manufacturing. Two of the major transformations that have taken hold in manufacturing, namely "Lean" and "Industry 4.0", have been examined and have shown great promise in the construction industry. Consequently, the terms "Lean Construction" and "Construction 4.0" emerged in the construction body of knowledge.

Lean construction emerged as a new concept in the mid-1990s that introduced a novel theory-based approach to the construction industry with a kit of tools and methods adopted from Toyota's Lean production (Koskela et al. 2002). Lean construction is also a "respect- and relationship-oriented production management-based approach to project delivery" which changes the traditional of way of designing, building, supplying, and delivering construction projects (Seed 2015). While Lean challenges the traditional management practices, the recent Construction 4.0 transformation leverages the power of technology. Modeled after Industry 4.0 (or the fourth industrial revolution), Construction 4.0 is inspired by the convergence of trends and technologies to plan, design, deliver, and operate projects more effectively and efficiently (Sawhney et al. 2020b). The European Construction Industry Federation (FIEC) defines Construction 4.0 as a "significant transformation for the construction industry which includes revolutionary approaches such as digitalization and automation" (FIEC 2020). Construction 4.0 has four major design principles: (1) interconnection and interoperability to support effective communication and coordination among stakeholders, (2) information transparency, (3) decentralized decision making, and (4) technical assistance for construction personnel (Hossain and Nadeem 2019; Noran et al. 2020). Technologies enabling Construction 4.0 include big data, virtual reality (VR), augmented reality (AR), sensors, robotics, artificial intelligence (AI), 3D printing, drones, and integrated Building Information Modelling (iBIM), in addition to currently used software tools such as Computer-Aided Design and Drafting (CAD), Enterprise Resource Planning (ERP), and Customer Relationship Management (CRM) (Bou Hatoum et al. 2020; Noran et al. 2020; Rastogi 2017).

While volumes have been written on Lean Construction, the exploration of the path towards Construction 4.0 is on the rise. Researchers have investigated Construction 4.0 technologies and their potential associated benefits. However, an important topic that has not been discussed yet is the absence of a construction process reengineering 
methodology that accounts for the proper integration of the technologies (Oesterreich and Teuteberg 2016). Existing construction processes have been mostly designed before current technologies became available, and thus, cannot undergo transformations without being reengineered (El Jazzar et al. 2020). While technology integration is at the core of the needed process reengineering methodology, focusing solely on technology has the potential to fail in the construction industry (Love et al. 1996). For this methodology to be a recipe for success, it should be three-pronged and combine technology, human, and organizational aspects (Love et al. 1996). Additionally, the methodology should leverage and be supported by existing transformations to maximize the expected value. Therefore, this paper, which is part of an ongoing study, proposes a holistic conceptual framework that leverages on Lean construction to reengineer construction processes in the era of Construction 4.0. The framework, named "Construction 4.0 Process Reengineering" or "CPR4.0", is developed for construction companies to assist them in their Construction 4.0 reengineering efforts.

\section{METHODOLOGY}

The methodology adopted to develop the framework follows a design science approach that can be summarized in four tasks: (T1) reviewing the existing research corpus to understand construction industry transformations and highlight gaps in existing process reengineering methodologies, (T2) presenting a new framework to reengineer construction processes, (T3) verifying the framework with subject matter experts through interviews and surveys, and (T4) validating the framework through applying it on a reallife construction process. This paper will be limited only to T2, where an initial draft of the framework will be presented, and its lean aspect will be discussed.

\section{PROPOSED FRAMEWORK}

\section{RATIONAL AND VISION BEHIND CPR4.0}

The growing need for change and improvement has led the construction industry to embrace technologies to shape its future. Therefore, the proposed CPR4.0 framework is envisioned as a vehicle that can assist in moving the construction industry towards its future. CPR4.0 provides a holistic framework to reengineer construction processes while properly and effectively integrating technology. In the discourse about the future, the "Futures Triangle" methodology was put fore to map the anticipated future. Developed by Inayatullah (2008), the Futures Triangle (as illustrated in the left of Figure 1) maps the competing dynamics between the past, present, and future contexts. Each dimensions represent a set of drivers or factors that interact to contribute to the plausible future.

When considering CPR4.0, the equilibrium between the three dimensions is crucial for reaching the plausible future. The three dimensions labelled as weight of the past, push of the present, and pull of the future are described below:

The weight of the past, or the hindsight into the past, is represented by the resistance to change that is embedded in the construction industry and hesitance to adopt new technologies. The industry still relies on its traditional and conventional methods and processes resulting in a poor performance record as compared to other industries. Thus, the proposed framework will thoroughly understand the current state of the process to remove all constraints that may hinder the desired future process.

The push of the present, or the insight into present day, is represented by the current trends and quantitative drivers that are pushing for reengineering the construction 
processes. Examples of these trends include industry fragmentation, labour shortage, aging workforce, low productivity, and cost and schedule overruns. These drivers describe the current landscape of the construction industry, provide momentum for the future, and need to be carefully examined and accounted for in CPR4.0.

The pull of the future, or the foresight about the future, is envisioned as the enhanced image of the construction industry powered through Construction 4.0. This image of the construction future should empower people and embrace the use of technology in the industry to enable Construction 4.0 potential benefits. Thus, the proposed framework should not only result in a reengineered process that utilizes current technology, but also provide the reengineered process with enough room to adopt change and continuously improve with time.
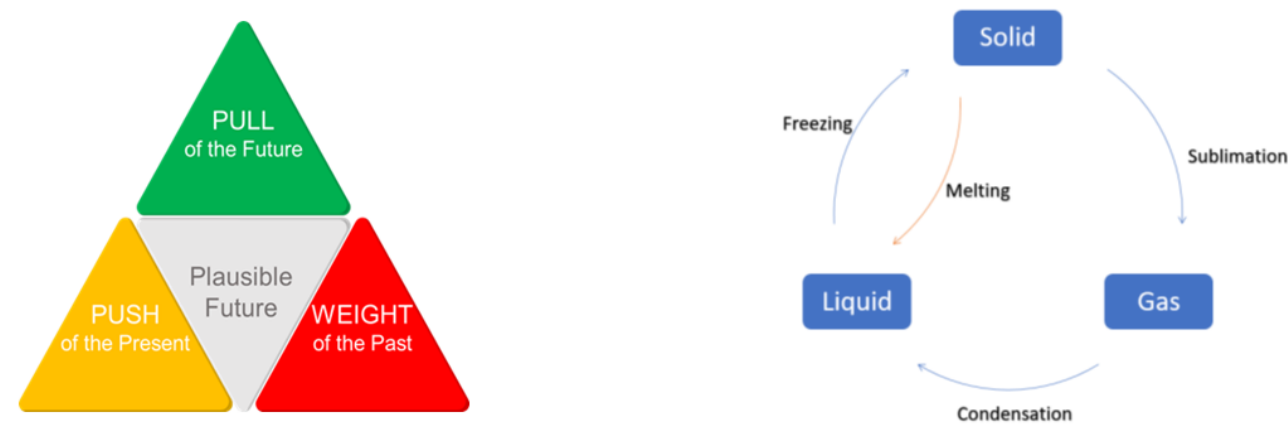

Figure 1: To the left, Futures Triangle reproduced from Inayutallah (2008); To the right, Schematic Diagram of CPR4.0

\section{FRAMEWORK INSPIRATION}

Lewin (1951) developed a three-stage model for change known as unfreezing-changerefreeze model. The model called the Kurt Lewin Change Management Model is a method to approach change management: (1) find the motivation to change and unfreeze the process, (2) change what needs to be changed to move to a new stage, and (3) refreeze the process and make the change permanent (Wirth 2004). Inspired by this model and the science behind the state of matter, CPR 4.0 can be mapped onto the distinct forms in which a matter can exist. As illustrated in Figure 2, reengineering transforms an existing process from its solid state to gas through sublimation, from gas to liquid through condensation, and then from liquid to solid through freezing which marks the beginning of a new cycle of the reengineered process. Within this external cycle, an internal melting-freezing cycle is also introduced to account for continuous improvement. These phases are aligned with the various process reengineering methodologies developed for the construction industry (Cheng and Tsai 2003; Mao and Zhang 2008; Mendonça and McDermott 2000; Serpell et al. 1996) where reengineering is described as a cycle that begins by first selecting the process to change, diagnosing the process by understanding its current state, designing the future state, implementing the designed future state, and continuously evaluating and improving the process. The CPR4.0 phases are explained in the following section, and the detailed elements of the proposed framework are shown in Figure 2.

The schematic diagram of the proposed CPR4.0 illustrates the cycle of fundamentally rethinking and radically redesigning a construction process, an act that has its root in Lean production. In his book about The Toyota Way, Liker identified 14 principles that explain Toyota's unique approach to Lean management and noted that principles are valuable insights that can be applied to any process. Skaar (2019) noted that when reengineering a process, Lean thinking needs to be first promoted and supported before pushing Lean tool 
into the reengineered process. Imposing Lean tools on process participants may clash with know-how causing resistance to change (Skaar 2019). The focus on the tools rather than the thinking can also misguide the purpose of the reengineering initiative (Skaar 2019). Therefore, Lean thinking and Lean principles need to be instilled into any construction process reengineering effort. Additionally, researchers have indicated that Lean can support Industry 4.0 (Buer et al. 2018; Pagliosa et al. 2019), thus, highlighting that Lean principles must be inculcated into a Construction 4.0 process reengineering methodology. The proposed CPR4.0 framework is discussed in the following section, followed by the integration of the Lean principles across its phases where Sublimation is referred to as Phase I, Condensation as Phase II, and Freezing/Melting cycle as Phase III.

\section{FrameWORK PHASES}

A review of the existing reengineering methodologies coupled with the people-processtechnology methodology formed the basis for developing the CPR4.0 framework. Researchers noted that any process reengineering methodology that focuses only on technology has the potential to fail in the construction industry; therefore, combining human, process, and technology aspects was a core idea for building the holistic framework (Love et al. 1996). Thus, each phase of the proposed CPR4.0 framework is discussed in terms of people, process, and technology as detailed in Figure 2. A prerequisite for employing CPR4.0 is for the construction company to choose a process to reengineer. The process is assumed to be in its current solid state having its fixed tasks, participants, end-users, information, technology, and its interactions with the external environment. It should be noted that the selection of the process is outside the scope of this paper.

Once a selection has been made, the chosen process needs to be first understood. Thus, the process is broken down into its smallest particles (i.e., components) to understand its status quo. This breakdown changes the state of the process form solid to gas, and the process is hence called sublimation. The understanding of the process will allow us to map it out for diagnosis and reengineering. The understanding happens at three levels: people, process, and technology.

Then, after mapping out and diagnosing the process, the status quo needs to be changed and the future state envisioned. At this point, the process is being transformed into its liquid state, where the company can control and mold the flow of the process: it can add, modify, reorder, change, and/or remove any of the components of the existing process as the future process is being established. This step is thus called condensation, where the reengineering process moves the existing process from its gas to its liquid state.

After that, once the future state is mapped out and all constraints are removed, the future state process can be implemented. Implementing the new process means fixing its components, so the liquid state is now frozen to a new solid-state process.

Finally, the process needs to be monitored for success. If the success metrics are not achieved, the process is melted again to the liquid phase for changes. The process can also be melted for improvement, or if external factors such as the rise of new technology can impact the process. This melting/freezing cycle is thus a representation of the continuous improvement cycle.

\section{Mapping of Lean Principles}

Principle 1 - "Base your management decisions on a long-term philosophy, even at the expense of short-term financial goals" (Phases I, II, and III): Basing decisions on a "long- 
term philosophy" should be applied throughout the entire framework. Every decision taken in any phase should not hinder the tasks or the work happening in the subsequent phases.

Principle 2 - "Create a continuous process flow to bring problems to the surface" (Phase II): Creating continuous flow when designing the future state of the process is crucial. This can be achieved by removing waste and creating an uninterrupted flow of materials and information needed for the different tasks of the process (Intrieri 2018). Once this is achieved in Phase II, it will automatically be implemented in Phase 3 where the envisioned process is continuously evaluated and improved.

Principle 3 - "Use pull systems to avoid overproduction" (Phase II): Using the "pull" system is essential in Phase II. When envisioning the future state of the process, information for example should be provided to people or technology when needed (Liker 2004). In other words, it is important to pull information from later phases to be used earlier in the framework.

Principle 4 - "Level out the workload, i.e. heijunka" (Phase II): Levelling out the workload (Heijunka) is important in Phase II when envisioning the future process. For example, roles and responsibilities should be distributed between people in a manner that keeps them focused on performing added-value work without being overburdened (Intrieri 2018; Kilpatrick 2003).

Principle 5 - "Build a culture of stopping to fix problems, to get quality right the first time" (Phases II and III): Building a culture to stop and fix problems (Jidoka) is applicable to Phases II and III. When envisioning the future state, people should be trained to detect problems and quickly solve them and provide countermeasures. Technologies being considered should also assist in doing so (Intrieri 2018). Applying this principle can reduce rework and detect errors to eliminate or mitigate them early (Nikakhtar et al. 2015).

Principle 6 - "Standardized tasks and processes are the foundation for continuous improvement and employee empowerment" (Phases I and II): Standardizing tasks can be of great help in Phases I and II. This would help those involved in the reengineering effort to understand all the necessary tasks and their requirements. It would also help detect waste and creating the process blueprints. Additionally, standardizing the thought process can ensure buy-in from and alignment among all involved parties.

Principle 7 - "Use visual control so no problems are hidden" (Phases I, II, and III): Using visual control is extremely important through the entire phases of the framework. It can facilitate discussing ideas, solving problems, standardizing tasks, mapping processes, and reporting progress.

Principle 8 - "Use only reliable, thoroughly tested technology that serves your people and processes" (Phases II and III): Using technology that will not disturb the process is key to a practical reengineering effort. Technology should be reliable, predictable, and able to serve both the people and the process (Liker 2004).

Principle 9- "Grow leaders who thoroughly understand the work, live the philosophy, and teach it to others" (Phases I, II, and III): Empowering leaders or "champions" who advocate for the use of technology and motivate people to change is essential for the reengineering process (Andipakula 2017). A strong champion would be able to motivate co-workers to overcome their hesitance, try new things outside their comfort zone, and direct the efforts towards achieving the common objective(s) (Shohet and Frydman 2003).

Principle 10 - "Develop exceptional people and teams who follow your company's philosophy" (Phases I, II, and III): Developing exceptional people and cross functional 
teams that work together in all three Phases is a must for a seamless transfer of knowledge and implementation of the premise of framework.

Principle 11 - "Respect your extended network of partners and suppliers by challenging them and helping them improve" (Phases I, II, and III): Respecting the extended network of partner and suppliers is important through ought the entire reengineering process. The needs of stakeholders affected by the process should be investigated in both the current and future stat. Moreover, the reengineered process should aim to empower and assist the external entities affected by the future state process. For example, a contractor implementing a certain technology can assist the subcontractors in adopting that technology as well, especially if it serves projects and enhances the work.

Principle 12 - "Go and see for yourself to thoroughly understand the situation" (Phases I, II, and II): Go and see for yourself (Genchi Genbutsu) must be practiced throughout the three Phases. Those involved in the process and those impacted need to be engaged in the reengineering effort to ensure that the process is being improved for the greater benefits of everyone (Intrieri 2018).

Principle 13 - "Make decisions slowly by consensus, thoroughly considering all options and then implement rapidly" (Phase II): Making decisions slowly and implementing them rapidly (Nemawashi) can be leveraged in Phase II. People responsible for change should take their time in analysing the current state and making decisions for the future ones. Once all decisions are taken carefully and thoroughly, implementing the new process should be rapid.

Principle 14 - "Become a learning organization through relentless reflection and continuous improvement" (Phases I, II, and III): Using reflection (Hansei) and continuous improvement (Kaizen) should be an integral part of the framework from beginning to end. People participating in the reengineering initiative should continuously reflect on their work and asses their progress to learn from mistakes and improve their future performance.

\section{CONCLUSIONS AND FUTURE WORK}

Achieving a plausible future for the construction industry is a long journey. Lean Construction and Construction 4.0 are two major transformations that play a central role in rethinking existing construction processes to empower construction personnel and leverage the power of technology. While the importance of Construction 4.0 has been highlighted, the "how" component of achieving a Construction 4.0 state has not been yet discussed. A process reengineering methodology is needed to assist construction companies in adopting technologies. This paper is a first step of an ongoing effort to meet the need of the construction industry. This paper proposes a holistic conceptual framework to reengineer construction processes in the Construction 4.0 era. The proposed Construction 4.0 Process Reengineering (CPR4.0) framework, which embodies the Futures Triangle methodology and is inspired by Kurt Lewin Change Management Model, consists of three phases that build on existing reengineering methodologies, peopleprocess-technology methodology, and Lean principles. Each phase of CPR4.0 consists of several tasks which, collectively, lead to a reengineering a process through the lens of Construction 4.0. The work presented in this paper is conceptual and will be expanded on in two future steps: verify the framework through structured interviews with subject matter experts and validate the applicability of CPR4.0 through an implementation in action case study. 


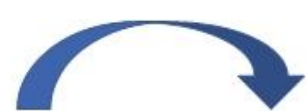

Understand the status quo and map out the current process

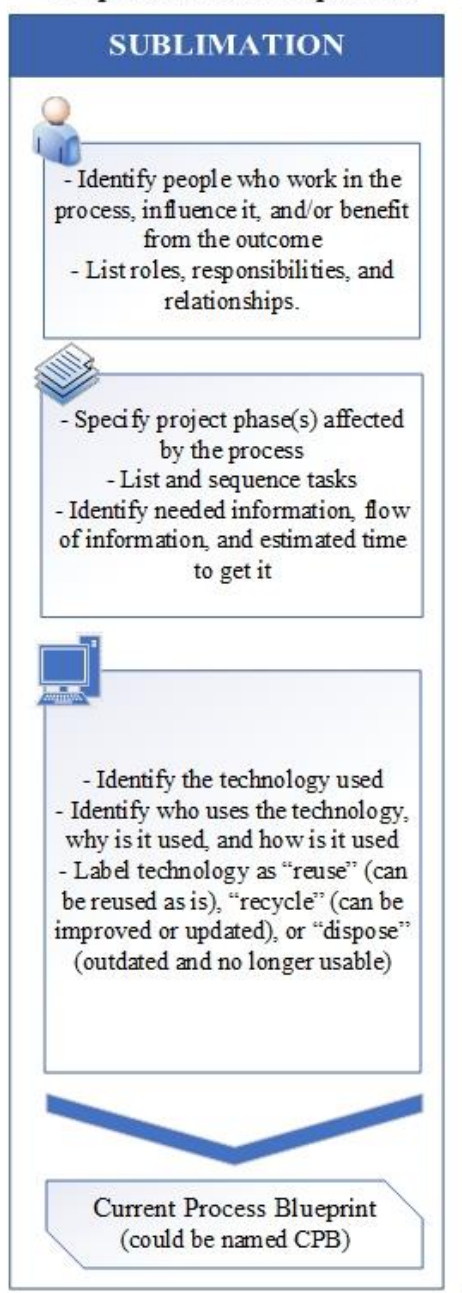

Change the status quo and envision the new process

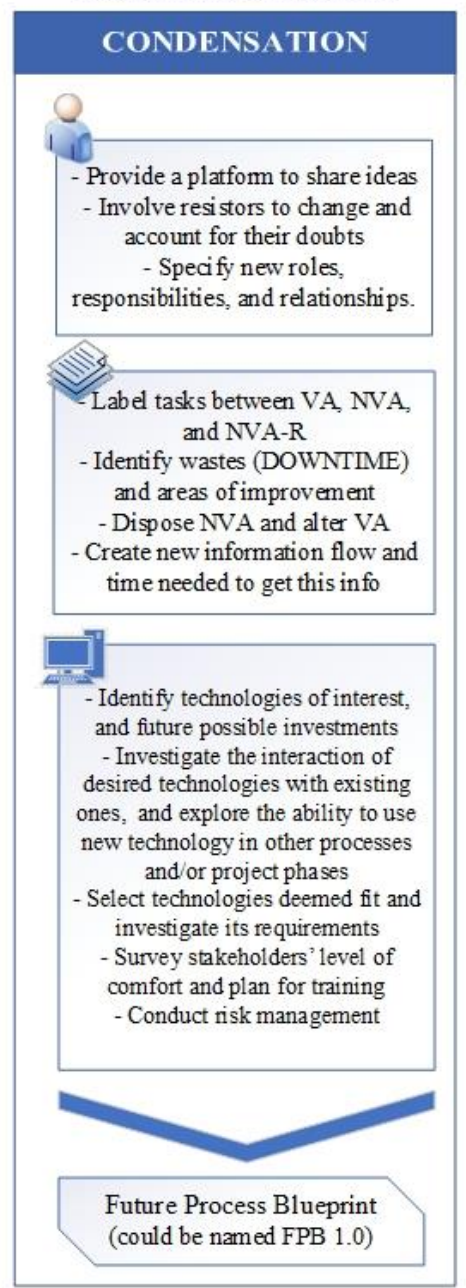

Principles $2,3,4, \& 13$

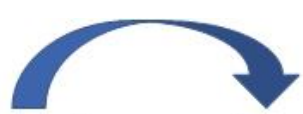

Assess and improve continuously

\section{FREEZING/MELTING}

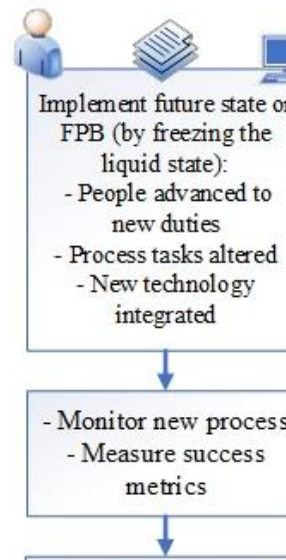

Unfreeze the new process (by melting the solid state to the liquid form) in case of any positive or negative apprises

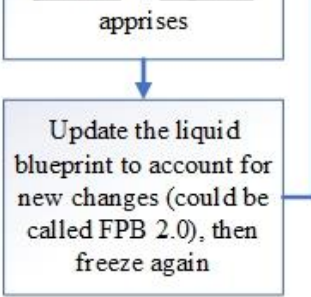

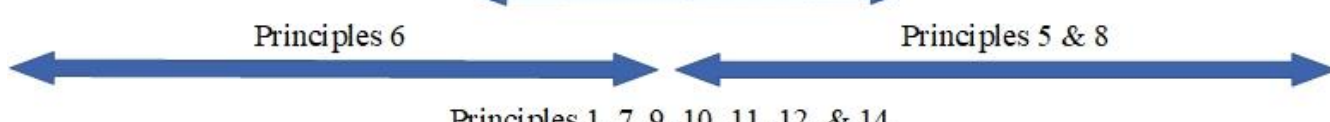

Principles $1,7,9,10,11,12, \& 14$

Figure 2: Proposed CPR4.0 Framework

\section{REFERENCES}

Adesola, S., and Baines, T. (2005). "Developing and evaluating a methodology for business process improvement." Business Process Management Journal, Emerald Group Publishing Limited, 11(1), 37-46.

Andipakula, T. (2017). "Case study of barriers inhibiting the growth of information and communication technology (ICT) in a construction firm, A." PhD Thesis, Colorado State University.

Barbosa, F., Woetzel, J., Mischke, J., Ribeirinho, M. J., Sridhar, M., Parsons, M., Bertram, N., and Brown, S. (2017). Reinvinting Construction: A Route to Higher Productivity. McKinsey Global Institute. 
Bou Hatoum, M., and Nassereddine, H. (2020). "Developing a Framework for the Implementation of Robotics in Construction Enterprises." EG-ICE 2020 Proceedings: Workshop on Intelligent Computing in Engineering, Germany, 453-462.

Bou Hatoum, M., Piskernik, M., and Nassereddine, H. (2020). "A Holistic Framework for the Implementation of Big Data throughout a Construction Project Lifecycle." Proceedings of the 37th International Symposium on Automation and Robotics in Construction (ISARC), Kitakyushu, Japan, 1299-1306.

Buer, S.-V., Strandhagen, J. O., and Chan, F. T. (2018). "The link between Industry 4.0 and lean manufacturing: mapping current research and establishing a research agenda." International Journal of Production Research, Taylor \& Francis, 56(8), 2924-2940.

Cheng, M.-Y., and Tsai, M.-H. (2003). "Reengineering of construction management process." Journal of construction engineering and management, American Society of Civil Engineers, 129(1), 105-114.

El Jazzar, M., Urban, H., Schranz, C., and Nassereddine, Ha. (2020). "Construction 4.0: A Roadmap to Shaping the Future of Construction." Proceedings of the 37th International Symposium on Automation and Robotics in Construction, Kitakyshu, Japan, 1314-1321.

FIEC. (2020). "Digitalisation, Construction 4.0 and BIM." European Construction Industry Federation Priorities.

Hammer, M., and Champy, J. (2009). Reengineering the Corporation: A Manifesto for Business Revolution. Zondervan.

Hossain, M. A., and Nadeem, A. (2019). "Towards digitizing the construction industry: State of the art of construction 4.0." Proceedings of International Structural Engineering and Construction ·, ISEC Press.

Inayatullah, S. (2008). "Six pillars: futures thinking for transforming." Foresight, Emerald Group Publishing Limited, 10(1), 4-21.

Intrieri, C. (2018). "14 Principles of Lean Toyota Production System (TPS).” Flevyblog.

Kilpatrick, J. (2003). "Lean Principles." Utah Manufacturing Extension Partnership, 68(1), 1-5.

Koskela, L., Howell, G., Ballard, G., and Tommelein, I. (2002). "The foundations of lean construction." Design and construction: Building in value, Oxford, UK: ButterworthHeinemann, Elsevier, 291, 211-226.

Lau, S. E. N., Zakaria, R., Aminudin, E., Saar, C. C., Abidin, N. I. A., Roslan, A. F., Abd Hamid, Z., Zain, M. Z. M., and Lou, E. (2019). "Identification of roadmap of fourth construction industrial revolution." IOP Conference Series: Materials Science and Engineering, IOP Publishing, 012029.

Lewin, K. (1951). Field theory in social science: selected theoretical papers (Edited by Dorwin Cartwright.). Harpers.

Liker, J. K. (2004). The Toyota Way: 14 Management Principles drom the World's Greatest Manufacturer. McGraw-Hill.

Love, P. E. D., MAcSporran, C., and Tucker, S. N. (1996). "The Application of Information Technology by Australian Contractors: Toward Process Re-Engineering." 4th Annual Conference of the International Group for Lean Construction, Birmingham, UK.

Mao, X., and Zhang, X. (2008). "Construction process reengineering by integrating lean principles and computer simulation techniques." Journal of construction Engineering and Management, American Society of Civil Engineers, 134(5), 371-381. 
Mellado, F., and Lou, E. C. (2020). "Building information modelling, lean and sustainability: An integration framework to promote performance improvements in the construction industry." Sustainable Cities and Society, Elsevier, 61, 102355.

Mendonça, L. V., and McDermott, P. (2000). "Lean Design Management Applied to Concrete Structures for Retaining Aqueous Liquids: A Redesign Process Model to Portuguese Design Companies." Brighton, UK.

Nassereddine, H. M. (2019). Design, Development and Validation of an Augmented Reality-Enabled Production Strategy Process for the Construction Industry. The University of Wisconsin-Madison.

Nikakhtar, A., Hosseini, A. A., Wong, K. Y., and Zavichi, A. (2015). "Application of lean construction principles to reduce construction process waste using computer simulation: a case study." International Journal of Services and Operations Management, Inderscience Publishers, 20(4), 461-480.

Noran, O., Romero, D., and Burchiu, S. (2020). "Exploring the Path Towards Construction 4.0: Collaborative Networks and Enterprise Architecture Views." IFIP International Conference on Advances in Production Management Systems, Springer, Sad, Serbia, 547-556.

Oesterreich, T. D., and Teuteberg, F. (2016). "Understanding the implications of digitisation and automation in the context of Industry 4.0: A triangulation approach and elements of a research agenda for the construction industry." Computers in industry, Elsevier, 83, 121-139.

Pagliosa, M., Tortorella, G., and Ferreira, J. C. E. (2019). "Industry 4.0 and Lean Manufacturing: A Systematic Literature Review and Future Research Directions." Journal of Manufacturing Technology Management, Emerald Publishing Limited, ahead-of-print(ahead-of-print).

Rastogi, S. (2017). "Construction 4.0: The 4th Generation Revolution." Indian Lean Construction Conference, ILCC 2017, C288-C298.

Sawhney, A., Riley, M., and Irizarry, J. (2020a). Construction 4.0: an innovation platform for the built environment. Routledge, Abingdon, Oxon ; New York, NY.

Sawhney, A., Riley, M., Irizarry, J., and Pérez, C. T. (2020b). "A proposed framework for Construction 4.0 based on a review of literature." EPiC Series in Built Environment, EasyChair, 1, 301-309.

Seed, W. R. (2015). Transforming Design and Construction: A Framework for Change. Lean Construction Institute.

Serpell, A., Alarcón, L. F., and Ghio, V. (1996). "A general framework for improvement of construction process." Annual Conference of the International Group for Lean Construction.

Shohet, I. M., and Frydman, S. (2003). "Communication patterns in construction at construction manager level." Journal of construction engineering and management, American Society of Civil Engineers, 129(5), 570-577.

Skaar, J. (2019). "The Power of Lean Principles." Proc. 27th Annual Conference of the International Group for Lean Construction (IGLC), Dublin, Ireland, 393-404.

Widodo, S. M., Astanti, R. D., Ai, T. J., and Samadhi, T. M. A. A. (2020). "Seven-waste framework of waste identification and elimination for computer-based administrative work." The TQM Journal, Emerald Publishing Limited, ahead-of-print(ahead-ofprint).

Wirth, R. A. (2004). “Lewin/Schein's change theory.” Citeseer. 